\title{
Deep brain stimulation for vocal tremor: a comprehensive, multidisciplinary methodology
}

\author{
*Allen L. Ho, MD, ${ }^{1}$ Elizabeth Erickson-DiRenzo, PhD, ${ }^{2}$ Arjun V. Pendharkar, MD, MS, ${ }^{1}$ \\ Chih-Kwang Sung, MD, MS, ${ }^{2}$ and Casey H. Halpern, MD ${ }^{1}$
}

Departments of ${ }^{1}$ Neurosurgery and ${ }^{2}$ Otolaryngology (Head and Neck Surgery), Stanford University School of Medicine, Stanford, California

\begin{abstract}
Tremulous voice is a characteristic feature of a multitude of movement disorders, but when it occurs in individuals diagnosed with essential tremor, it is referred to as essential vocal tremor (EVT). For individuals with EVT, their tremulous voice is associated with significant social embarrassment and in severe cases may result in the discontinuation of employment and hobbies. Management of EVT is extremely difficult, and current behavioral and medical interventions for vocal tremor result in suboptimal outcomes. Deep brain stimulation (DBS) has been proposed as a potential therapeutic avenue for EVT, but few studies can be identified that have systematically examined improvements in EVT following DBS. The authors describe a case of awake bilateral DBS targeting the ventral intermediate nucleus for a patient suffering from severe voice and arm tremor. They also present their comprehensive, multidisciplinary methodology for definitive treatment of EVT via DBS. To the authors' knowledge, this is the first time comprehensive intraoperative voice evaluation has been used to guide microelectrode/stimulator placement, as well as the first time that standard pre- and post-DBS assessments have been conducted, demonstrating the efficacy of this tailored DBS approach.
\end{abstract}

http://thejns.org/doi/abs/10.3171/2015.3.FOCUS1537

KEY WORDS deep brain stimulation; essential vocal tremor; essential tremor; dysphonia; ventral intermediate nucleus

$\mathrm{T}$ REMULOUS voice is a characteristic feature of a multitude of movement disorders, including essential tremor, orofacial dystonia, spasmodic dysphonia, Parkinson's disease (PD), and progressive supranuclear palsy, as well as other neurological diseases including stroke and myasthenia gravis. Perhaps one of the clearest associations exists between tremulous voice and essential tremor. Tremulous voice occurring in individuals diagnosed with essential tremor is referred to as essential vocal tremor (EVT). ${ }^{1}$ It has been estimated that up to $40 \%$ of individuals diagnosed with essential tremor also present with an EVT.48

In EVT, laryngeal, pharyngeal, and/or palatal muscles rhythmically oscillate at a rate of $4-8 \mathrm{~Hz}$, resulting in alterations in pitch and/or loudness of the voice. ${ }^{1}$ Perceptions of alterations in pitch and loudness correlate with acoustic modulations of fundamental frequency (F0) and intensity, respectively. Vocal symptoms of EVT are present across the majority of phonatory activities but are most promi- nent during sustained phonation of vowels., ${ }^{1,26}$ Although there appears to be substantial interspeaker variability in the regularity and intensity of F0 and amplitude modulations, individuals with EVT consistently report an increase in vocal effort that significantly worsens with anxiety and stress. ${ }^{18,26}$ The devastating impact of EVT on quality of life should not be ignored. For individuals with EVT, their tremulous voice is associated with significant social embarrassment and in severe cases may result in the discontinuation of employment and hobbies.

Tremulous voice is a symptom of laryngeal tremor, a multifaceted disorder characterized by both intralaryngeal and extralaryngeal movement. ${ }^{48}$ During laryngeal tremor, involuntary contraction of antagonistic skeletal muscles leads to an oscillatory movement of the laryngeal apparatus. Rhythmic contraction of intrinsic laryngeal muscles such as the thyroarytenoid and lateral and posterior cricoarytenoid muscles, extrinsic laryngeal muscles, pharyngeal muscles, and palatal muscles gives rise to a tremulous

ABBREVIATIONS AC-PC = anterior commissure-posterior commissure; DBS = deep brain stimulation; EVT = essential vocal tremor; F0 = fundamental frequency; PD = Parkinson's disease; STN = subthalamic nucleus; Vim = ventral intermediate nucleus.

SUBMITTED January 31, 2015. ACCEPTED March 26, 2015. INCLUDE WHEN CITING DOI: 10.3171/2015.3.FOCUS1537.

DISCLOSURE The authors report no conflict of interest concerning the materials or methods used in this study or the findings specified in this paper.

* Drs. Ho and Erickson-DiRenzo contributed equally to this work. 
voice. ${ }^{26}$ Tremulous voice may further be affected by involuntary contraction of accessory muscles used for voice production, including the diaphragm and muscles of the chest wall and abdomen.

\section{Assessment and Treatment of EVT}

EVT is typically evaluated through the combined efforts of an otolaryngologist specializing in assessment and treatment of voice disorders and a speech language pathologist. Current recommendations dictate that clinical identification, quantification, and characterization of EVT be conducted using a sustained phonatory vowel task during fiberoptic nasolaryngoscopic examination of pharyngeal and laryngeal musculature supplemented with acoustic measures. ${ }^{11}$ Transnasal endoscopy is preferred to oral endoscopy because it permits thorough evaluation of the pharynx and larynx in a more natural posture..$^{18}$ During transnasal endoscopy, rhythmic oscillatory motion of the vocal folds is considered diagnostic for laryngeal tremor. ${ }^{26}$ This is frequently accompanied by contractions of the palate and pharynx and/or oscillations of the larynx in a craniocaudal direction. Tremor may be observed during both quiet respiration and sustained vowel phonation.

It is critical that direct laryngeal examination be supplemented with acoustic measures. Acoustic evaluation of EVT is best performed using sustained phonation of vowels as tremor may be partially masked during connected speech. ${ }^{1}$ EVT is described acoustically by the rate of the F0 and intensity modulation. ${ }^{24}$ Typically, modulations in F0 tend to co-occur with intensity modulations. ${ }^{1}$ EVT may also be described by the magnitude of F0 and intensity modulation. Magnitude is evaluated by measuring the range of F0 and intensity oscillations. Additional instrumental measures of voice have included acoustic analysis of perturbation measures such as jitter, shimmer, and harmonic-to-noise ratio. Elevated jitter and shimmer and decreased harmonic-to-noise ratio are typical instrumental voice findings in patients with EVT. ${ }^{7}$

Historically, management of EVT has been extremely difficult. ${ }^{1}$ First-line treatment is medical, and propranolol and primidone have been used with variable results. ${ }^{18} \mathrm{~A}$ number of patients with EVT have also been treated with botulinum A toxin (Botox) injections into the thryroarytenoid muscle. However, in this instance, improved symptoms are dependent on a tremor that primarily involves the thryroarytenoid muscle. More recently, there have been reports that a subset of patients with EVT may benefit from behavioral intervention with a speech language

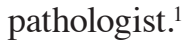

\section{DBS for EVT}

Overall, current behavioral and medical interventions for vocal tremor result in suboptimal outcomes. DBS has been characterized as a potential therapeutic avenue for approximately 15 years, but, to date, few studies can be identified that have systematically examined improvements in EVT following DBS. The first published case reports of DBS specifically for the treatment of vocal tremor were by Sataloff et al. in 2002. ${ }^{40}$ Two patients underwent bilateral stimulator implantation in the ventral intermedi- ate nucleus (Vim) and were evaluated by strobovideolaryngoscopy and objective voice analysis, with elimination of voice tremor in one patient and significant decrease in the other. ${ }^{40}$ Additional studies exist for vocal tremor but are either case reports or include data from a limited number of participants. ${ }^{4,28,49}$ Reductions in voice tremor have also been reported following DBS for patients with varied pathologies including essential hand tremor, ${ }^{4} \mathrm{PD}$-associated tremor ${ }^{42}$ and dystonia. ${ }^{12}$ Reductions in voice tremor were an ancillary result of DBS targeting the thalamus and associated thalamic nuclei. Voice tremor reduction did not mirror in magnitude the improvement seen in other areas of tremor. ${ }^{4,12,28,42}$ Similar results have been seen in DBS for PD, where traditional stimulation of the subthalamic nucleus (STN) and medication have demonstrated varied and inconsistent effects of improvement in voice tremor and vocalization. . $^{35,36,39,43,46}$

Here, we present a case of awake, bilateral DBS targeting the Vim in a patient suffering from severe voice and arm tremor. To our knowledge, this is the first time comprehensive intraoperative voice evaluation has been used to guide microelectrode/stimulator placement, as well as the first time that standard pre- and post-DBS voice assessments have been conducted, demonstrating the efficacy of this tailored DBS approach.

\section{Vim Target for DBS}

The usefulness of the Vim as an electrical stimulation target for the treatment of tremor was first discovered by Benabid et al. in $1987 .{ }^{3}$ As a conglomeration of the cerebellar afferents, the Vim has a strictly somatotopic organization, with the face occurring medially, followed by the hands and legs from medial to lateral (Fig. 1).14,16,25 The Vim is difficult to distinguish on MRI, and, as a result, stereotactic referencing is required for indirect targeting. ${ }^{21,37}$ Additionally, intraoperative physiological mapping with microelectrode recording is often necessary. ${ }^{2}$ The location of the Vim nucleus varies by individual, but is targeted approximately $12-14 \mathrm{~mm}$ lateral to the anterior commissure-posterior commissure (AC-PC) line and $6 \mathrm{~mm}$ posterior to the midpoint of the AC-PC. ${ }^{32}$ We target the Vim directly. As the microelectrode passes caudally along its course toward the Vim, activation of units begins to occur more with passive kinesthetic movement of extremity joints. ${ }^{27}$ Given that the somatotopic map of the thalamus has the receptive fields of the face medial, upper extremity ventromedial, and lower extremity dorsolateral, the standard dorsolateral-to-ventromedial track into the Vim encounters first leg and then arm passive kinesthetic receptive fields. The ventrooralis anterior and ventrooralis posterior nuclei are found just anterior to Vim where voluntary movements of the contralateral extremities drive tonic activity. ${ }^{22}$ The ventral caudalis nucleus is signaled by cutaneous receptive fields activated by very light touch in a narrow somatotopic region that distinguishes it from the Vim posteriorly. ${ }^{13,25}$ Precise definition of the border of the Vim with the ventral caudalis can assist in accurate electrode implantation a safe distance $(>2 \mathrm{~mm})$ from the ventral caudalis nucleus. ${ }^{2}$ The typical target for implantation of the DBS electrode for essential tremor is within the kin- 


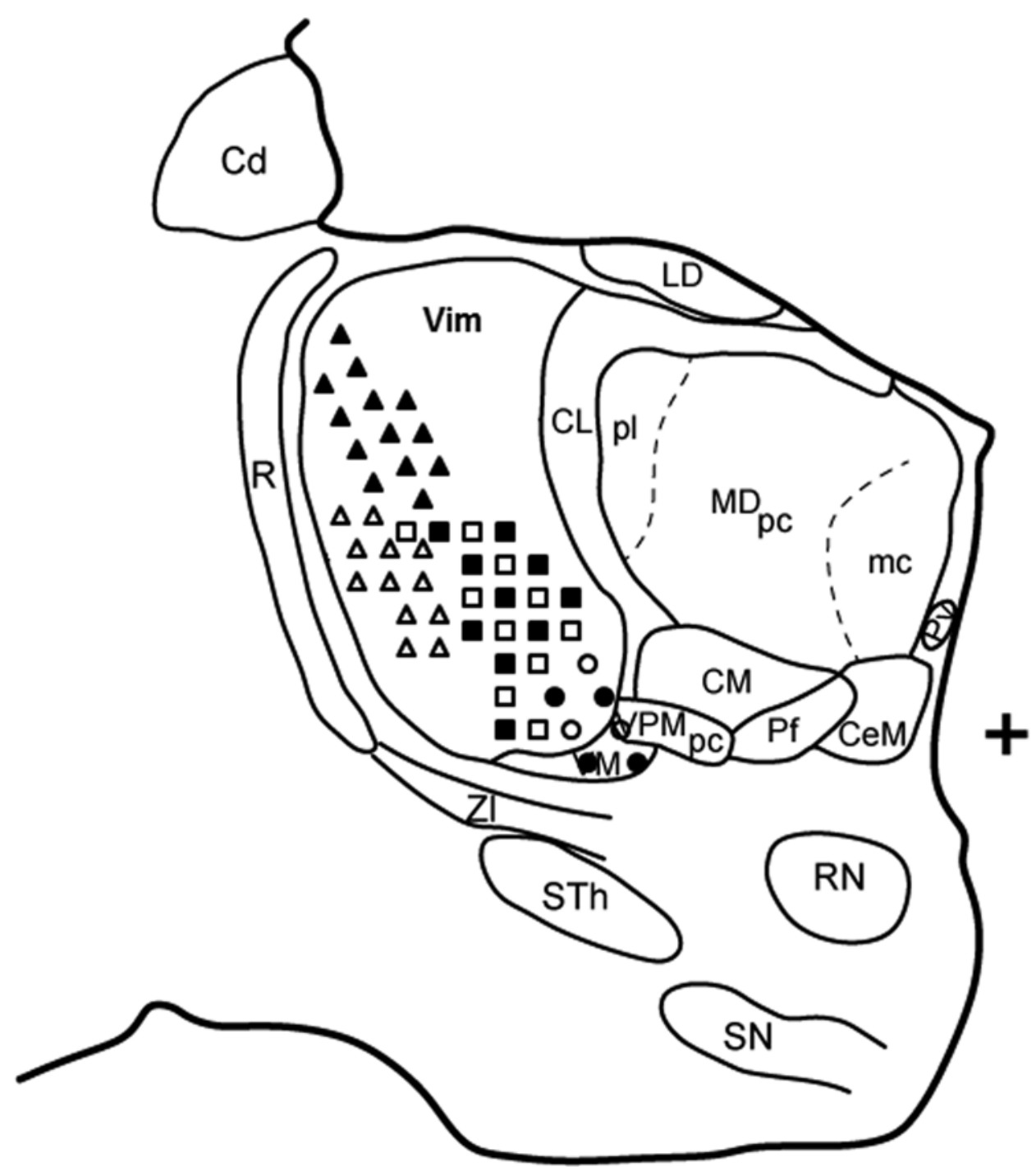

FIG. 1. Somatotopy of the Vim. Coronal section with somatotopic overlay of normal motor representation of the leg (open triangle), arm (open square), and face (open circle) in the primate Vim. Our microelectrode recording demonstrates a similar somatotopic alignment of arm (filled square) and face (filled circle), but with leg (filled triangle) occurring more superomedially. Information regarding the generation of this figure can be found in the work by Vitek et al. ${ }^{44} \mathrm{Cd}=$ caudate nucleus; $\mathrm{CeM}=$ central median nucleus; $\mathrm{CL}=$ central lateral nucleus; $\mathrm{CM}=$ centromedian nucleus; $\mathrm{LD}=$ lateral dorsal nucleus; $\mathrm{MDmc}=$ mediodorsal nucleus magnocellar; $\mathrm{MDpc}=$ mediodorsal nucleus parvocellular; $\mathrm{MDpl}=$ mediodorsal nucleus paramellar; $\mathrm{Pf}=$ parafascicular nucleus; $\mathrm{PV}$ = parvalbumin; $\mathrm{R}$ = reticular nucleus; $\mathrm{RN}=$ red nucleus; $\mathrm{SN}=$ substantia nigra; $\mathrm{STh}=$ subthalamic nucleus; VM = ventral medial nucleus; VPMpc = ventral posteromedial nucleus parvocellular; ZI = zona incerta; + = AC-PC line.

esthetic fields corresponding to the hand. Within the target Vim zone, microelectrode stimulation with currents up to $100 \mu \mathrm{A}$ and macroelectrode stimulation with currents as low as $0.2 \mathrm{~mA}$ should achieve complete or near-complete tremor suppression. ${ }^{2,8}$ Sensations of paresthesias elicited proximal to the ventral caudalis nucleus will distinguish within 10 seconds if stimulated from the Vim; thus, tremor suppression in the absence of sustained paresthesia is the goal during stimulation. ${ }^{2}$

\section{Case Report}

This 57-year-old woman had a lifelong history of essential tremor that worsened 7 years prior to presentation. She was started on propranolol, which initially relieved her symptoms. However, as her tremor progressed, she began to have voice tremor in addition to bilateral arm tremor that interfered with her activities of daily living and profession as a notary. On physical examination, the patient was noted to have tremor present throughout her body at rest and a quivering voice present at all times during conversation. Her tremor was approximately $3-5 \mathrm{~Hz}$ and of low amplitude, greater on the right side of her body than the left. The tremor was present at rest but exacerbated with any kind of reaching motion or with lifting of the lower extremities, consistent with the diagnosis of essential tremor. The rest of her neurological examination was unremarkable.

The patient was referred to a laryngologist (C.K.S.) who performed a preoperative flexible distal-chip laryngosco- 
py, revealing a diffuse rhythmic, involuntary oscillating laryngeal tremor involving the laryngeal and pharyngeal muscle with no other significant anatomical abnormalities appreciated (Video 1).

VIDEO 1. Video of preoperative laryngoscopy evaluation. Video laryngoscopic preoperative evaluation of essential vocal tremor prior to DBS. Copyright Casey H. Halpern. Published with permission. Click here to view with Media Player. Click here to view with Quicktime.

The patient was subsequently taken to the operating room for implantation of bilateral Vim DBS electrodes via a frameless approach with intraoperative microelectrode recording and electrophysiology. Given the medial-to-lateral facial-forelimb-hindlimb somatotopy of the thalamic motor nuclei, targets were chosen approximately 1-2 mm medial to the typical target for essential tremor to suppress voice tremor. ${ }^{44,45}$ The left Vim nucleus was targeted approximately $13 \mathrm{~mm}$ lateral to the AC-PC line and $6 \mathrm{~mm}$ posterior to the midpoint of the AC-PC. The right Vim nucleus was targeted approximately $12 \mathrm{~mm}$ lateral to the AC-PC line and $6 \mathrm{~mm}$ posterior to the midpoint of the AC-PC. Standard intraoperative microelectrode recording with electrophysiology was performed as well as detailed intraoperative voice function assessment (E.E.D.) during placement of the microelectrode (Tables 1 and 2).

In the first microelectrode pass, kinesthetic responses were encountered at the foot and the arm as we approached the Vim. These responses registered with passive range of motion of the foot $10-12 \mathrm{~mm}$ above target to the arm roughly 4-7 $\mathrm{mm}$ above target. There were kinesthetic responses to tongue movement from $3.6 \mathrm{~mm}$ above target to $1.1 \mathrm{~mm}$ above target. Along this depth there was also some kinesthetic response to upper-extremity passive range of movement. The base of the thalamus was encountered at 1 $\mathrm{mm}$ below target. Macrostimulation through the cannula was performed at a depth of $7 \mathrm{~mm}$ above target from 0.2 to $3 \mathrm{~mA}$ increasing in $0.2-\mathrm{mA}$ increments. The impedance was 0.47 . There were no clear paresthesias up to $3 \mathrm{~mA}$ and no involvement of the internal capsule. Her speech was less dysarthric, and there was some mild improvement in postural and action tremor, but tremor did not completely resolve at higher currents. Macrostimulation through the cannula at the target depth revealed paresthesias at 0.2 $\mathrm{mA}$ that was experienced over the entire right side of her body and into the right face. Therefore, a second pass was performed $2 \mathrm{~mm}$ anterior to the first pass. Microelectrode recording was similar but demonstrated a quieter background than the previous track. Macrostimulation was performed through the cannula at $10 \mathrm{~mm}$ above the target, at $5 \mathrm{~mm}$ above the target, and at the target depth. At 10 $\mathrm{mm}$ above target there was no evidence of adverse sensory or motor effects with some reduction but no resolution in tremor. At $5 \mathrm{~mm}$ above target, a similar pattern was found. At the target depth there was a threshold for paresthesias of $0.5 \mathrm{~mA}$, and clear tremor improvement at $1 \mathrm{~mA}$ both in the postural position and with action without any adverse effects. Her speech was tested, and results revealed some mild improvement even with cannula stimulation at $2 \mathrm{~mA}$. The paresthesias resolved within 5 seconds. With this excellent result, the deep brain stimulating lead was implanted along this track. The base of Contact 0 was placed at 0 $\mathrm{mm}$ of the target depth. Macrostimulation was performed in a monopolar mode through Contacts 0 through 3. Monopolar stimulation through Contact 2 revealed paresthesias in the face that were very transient. They involved the right hand and face and at $3 \mathrm{~V}$ but resolved in less than 5 seconds. There were no adverse effects with monopolar stimulation through Contacts 1 and 3. At this point the patient had a very good microlesioning effect and therefore there was not much tremor improvement to be seen. With this excellent result, the left Vim DBS lead was secured in place (Fig. 2). At this juncture the patient expressed significant fatigue and requested that the procedure be stopped. The patient also exhibited refractory hypertension during the case and the decision was made to stage the procedure.

The patient returned for follow-up placement of her left infraclavicular pulse generator 1 week later, and she underwent implantation of her contralateral right DBS lead 2 weeks after her initial procedure. The right Vim nucleus was targeted $12 \mathrm{~mm}$ lateral to the AC-PC line and $6 \mathrm{~mm}$ posterior to the midpoint of the AC-PC line in an attempt to better target the medial Vim. Targets for both stimulator placements were chosen approximately 1-2 mm medial to the typical target for essential tremor to suppress voice tremor. The second DBS lead was implanted in a similar manner to the first, with confirmation of adequate control of voice, arm, and leg tremor prior to implantation of the electrode. However, this second procedure also included detailed intraoperative voice recordings and analysis before and after placement of the DBS lead to evaluate for improvement in vocal function (Tables 1 and 2). Finally, the patient underwent placement of her right infraclavicular pulse generator 1 week later. The patient tolerated all procedures without difficulty or immediate complications. Postoperatively, from each DBS procedure, the patient experienced a persistent microlesioning effect with improvement in both extremity and voice tremor such that she was able to discontinue her medications. The patient

TABLE 1. Intraoperative acoustical analyses of tremor of 2-second sustained production of vowels by a patient with EVT

\begin{tabular}{ccccc}
\hline Vowels & Rate F0 Modulation in Hz & $\begin{array}{c}\text { Rate Intensity Modulation } \\
\text { in Hz }\end{array}$ & $\begin{array}{c}\text { Average Extent F0 Modulation } \\
\text { in \% (SD) }\end{array}$ & $\begin{array}{c}\text { Average Extent Intensity } \\
\text { Modulation in \% (SD) }\end{array}$ \\
\hline li/ stim off & 3.5 & 3.5 & $10.0(3.6)$ & $39.5(17.3)$ \\
\hline li/ stim on & 0.5 & 2.5 & $2.4(0.7)$ & $27.9(5.3)$ \\
\hline la/ stim off & 4 & 4 & $13.4(5.3)$ & $20.2(10.9)$ \\
\hline la/ stim on & 2.5 & 3 & $4.7(1.9)$ & $21.5(10.7)$ \\
\hline
\end{tabular}

stim = stimulation. 
TABLE 2. Further intraoperative acoustical analyses of 2-second sustained production of vowels by a patient with EVT

\begin{tabular}{lccccc}
\hline & & \multicolumn{2}{c}{ Voicing } & & \\
\cline { 3 - 5 } Vowels & Average F0 in Hz (SD) & Fraction Unvoiced Frames in \% & No. of Voice Breaks & Jitter in \% & Shimmer in dB \\
\hline li/ stim off & $335(21.2)$ & 0 & 0 & 0.8 & 0.6 \\
\hline li/ stim on & $248(6.3)$ & 0 & 0 & 0.3 & 0.9 \\
\hline la/ stim off & $179(12.5)$ & 0 & 0 & 0.8 & 0.4 \\
\hline la/stim on & $169(10.2)$ & 0 & 0.6 & 0.4 \\
\hline
\end{tabular}

underwent programming of her bilateral Vim DBS lead 2 weeks later with standard programming protocols to optimize extremity tremor reduction. Contact $2-$ was selected and programmed to an amplitude of $2.0 \mathrm{~V}$ bilaterally with excellent response in both extremity and vocal tremor.

Vocal tremor data were acquired intraoperatively during implantation of the patient's DBS leads and during the initial programming visit after bilateral lead placement was complete. Unfortunately, due to technical difficulties, intraoperative voice tremor data for the initial DBS implantation were not of high enough quality for analysis; thus, no conclusions about the laterality of treatment effects can be drawn. All measures of vocal tremor were taken at the point of optimally suppressed extremity tremor. Specifically, audio recordings of sustained vowel production were collected from the patient at a sampling rate of $50,000 \mathrm{~Hz}$. Vowel productions were collected in stimulation-off and stimulation-on conditions. Representative sustained productions of the vowels /a/ and /i/ were analyzed using the Praat Speech Analysis Program. A middle 2 -second portion of the vowel produced by the patient at a comfortable pitch and loudness was used for analysis. Acoustical analyses of tremor characteristics included determination of rate of F0 and intensity modulation and average extent of F0 and intensity modulation. Vowels were also analyzed for voice breaks, jitter, and shimmer. Data collected intraoperatively are displayed in Tables 1 and 2 while data collected at the programming visit are displayed in Tables 3 and 4. During the intraoperative visit reductions in the rate and average extent of F0 and intensity modulation was observed for both vowel productions in the stimulation-on and compared with the stimulationoff condition. No evident changes were observed in voicing, jitter, and shimmer. During the programming visit, the rate of F0 and intensity modulation remained consistent in the stimulation-on and stimulation-off conditions

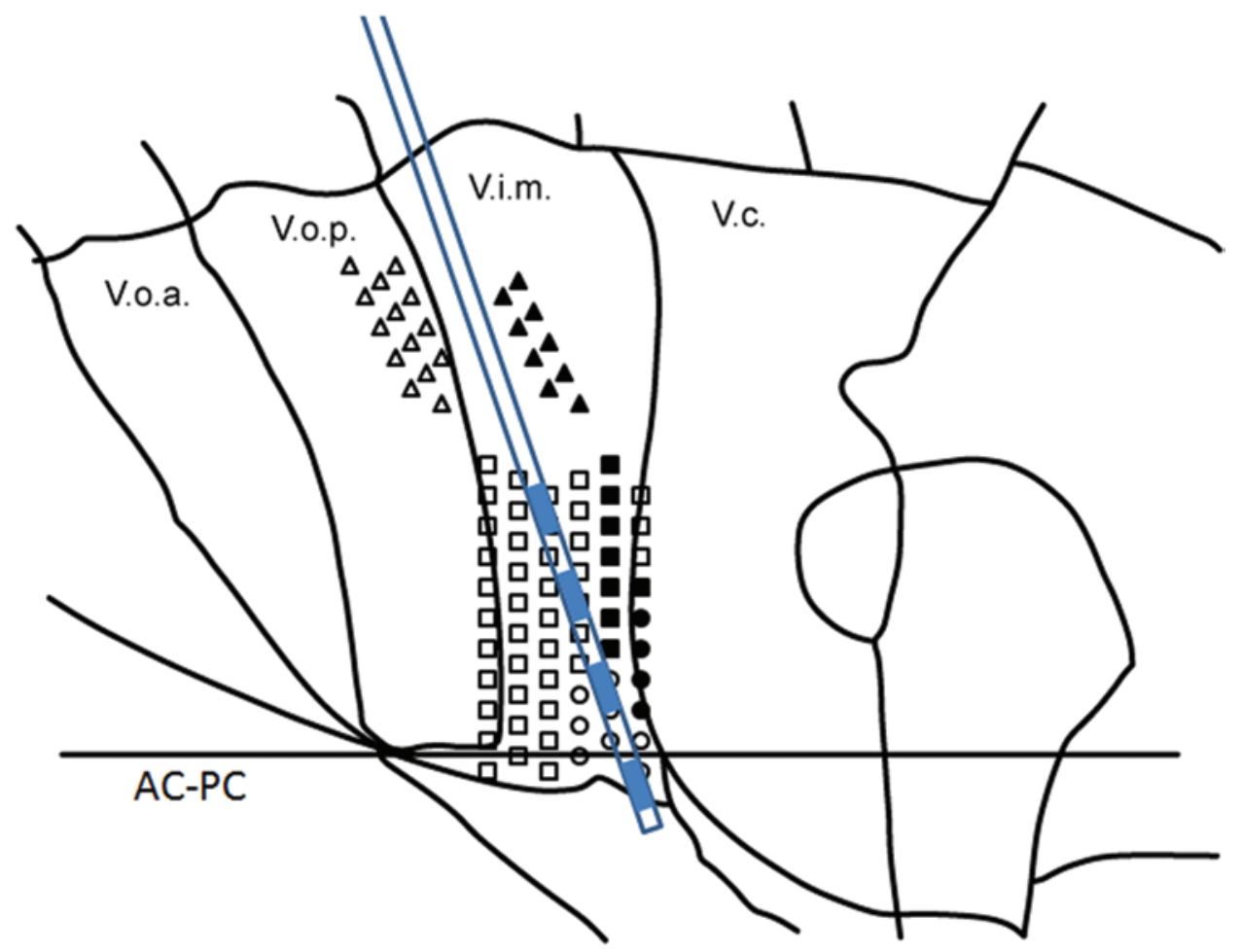

FIG. 2. DBS trajectory for EVT. Sagittal section of the Vim with somatotopic overlay of normal motor representation of the leg (open triangle), arm (open square), and face (open circle) in the human Vim demonstrating final placement of our DBS lead (blue) for treatment of EVT. Somatotopic findings of motor tracks from our microelectrode recording also displayed with similar somatotopic alignment of arm (filled square) and face (filled circle), but with leg (filled triangle) occurring more anteriorly. Information regarding the generation of this figure can be found in the works by Hua and Lenz ${ }^{15}$ and Lenz et al. ${ }^{23}$ V.c. $=$ ventral caudalis nucleus; V.o.a. = ventrooralis anterior nucleus; V.o.p. = ventrooralis posterior nucleus. 
TABLE 3. Acoustical analyses of tremor of 2-second sustained production of vowels by a patient with EVT following DBS placement

\begin{tabular}{lcccc}
\hline Vowels & Rate F0 Modulation in $\mathrm{Hz}$ & $\begin{array}{c}\text { Rate Intensity Modulation } \\
\text { in } \mathrm{Hz}\end{array}$ & $\begin{array}{c}\text { Average Extent F0 Modulation } \\
\text { (SD) }\end{array}$ & $\begin{array}{c}\text { Average Extent Intensity } \\
\text { Modulation (SD) }\end{array}$ \\
\hline li/ stim off & 4 & 3.5 & $3.7(1.8)$ & $24.5(18.1)$ \\
\hline li/ stim on & 4 & 3.5 & $2.0(0.5)$ & $21.0(4.1)$ \\
\hline la/ stim off & 3.5 & 4.5 & $13.4(5.3)$ & $35.6(10.5)$ \\
\hline la/ stim on & 4 & 3.5 & $4.7(1.9)$ & $29.5(3.9)$ \\
\hline
\end{tabular}

for both /i/ and /a/ vowel productions. However, reductions in the average extent of $\mathrm{F} 0$ and intensity modulations were observed for both vowel productions in the stimulation-on condition. In addition, for the /a/ vowel production we observed a reduction in the number of voice breaks and fraction of unvoiced frames as well as in jitter. Perceptually, these findings correlated with a less audible vocal tremor both intraoperatively and at the programming visit. The voice assessment procedures used for this investigation require only a microphone, a laptop, and acoustic software freely available online. These procedures can be readily applied by speech language pathology and otolaryngology professionals to assess EVT during DBS implantation surgery.

\section{Discussion}

Here, we report the successful treatment of EVT using awake, frameless DBS guided by intraoperative voice analysis. We used specific Vim neurophysiological targets and real-time feedback in the operating room to modulate speech, and we produced successful control of vocal tremor without diminishing any DBS treatment effect of concurrent extremity tremor. Further study is necessary to determine optimal target locations to simultaneously address multiple tremor types that may commonly occur together. Long-term follow-up is also needed to validate these clinical results.

Our case report represents a proof of concept and highlights the ongoing need for further studies and larger clinical trials of DBS in vocal tremor. EVT is only one indication for DBS. Our multidisciplinary approach with rigorous preoperative, intraoperative, and postoperative voice testing can be expanded for other voice disorders including those related to PD and dystonia.

\section{PD-Related Voice Disorders}

PD-related voice disorders affect between $70 \%$ and $90 \%$ of PD patients and manifest as hypokinetic dysar- throphonia, which is characterized by alterations in verbal communication, including hoarse voice, hypophonia, slurring together of syllables, and speech hesitation. ${ }^{38}$ While many studies exist in the literature reporting improvement in specific parameters of vocal measures in PD patients following STN DBS, $5,6,9,10,20,33,41$ stimulation-related dysarthria is also experienced in nearly $10 \%$ of PD patients with STN DBS..$^{19}$ Closer study of the somatotopy of the STN from primate anatomical studies reveal spatial distinctions between cells responding to orofacial movements (dorsal and rostrally located) versus those responding to limb (arm more lateral and leg more medial) movements. ${ }^{47} \mathrm{In}$ fact, dual inputs exist from both primary motor cortex as well as the supplementary motor area that are somatotopically mirrored within the STN with limb inputs occurring in central zones in a mediolateral distribution and orofacial inputs along the dorsal/rostral and most mediolateral extents of the STN. ${ }^{30}$ Determination of optimal stimulus locations for specific PD voice-related symptoms with STN DBS is likely related to this somatotopic organization of the STN, and treatment of limb-related movement disorder versus other manifestations of PD (such as orofacial, dysarthrophonia, and head/neck rigidity symptoms) will likely depend on more precise electrode placement with this organization.

\section{Spasmodic Dysphonia}

Spasmodic dysphonias are the most common subset of the laryngeal dystonias $;{ }^{17} 90 \%$ of these focal, action-specific laryngeal muscle spasms involve the adductor muscle. Electromyography-guided thyroarytenoid botulinum A toxin injection is the current standard of treatment but is plagued by loss of phonatory volume, dysphagia, and need for repeat injections every 3 months. ${ }^{34}$ Efficacy of botulinum A toxin treatment of abductor spasmodic dysphonia is more variable than the adductor variety. DBS already plays a prominent role in the treatment of primary generalized dystonia with validated targets in the internal glo-

TABLE 4. Further acoustical analyses of 2-second sustained production of vowels by a patient with EVT following DBS placement

\begin{tabular}{lcccccc}
\hline & & \multicolumn{2}{c}{ Voicing } & & \\
\cline { 3 - 5 } Vowels & Average F0 in Hz (SD) & Fraction Unvoiced Frames in \% & No. of Voice Breaks & Jitter in \% & Shimmer in dB \\
\hline li/ stim off & $373(12.5)$ & 0 & 0 & 0.5 & 0.4 \\
\hline li/stim on & $331(5)$ & 0 & 3 & 0.2 & 0.7 \\
\hline la/ stim off & $213(55.5)$ & 3.4 & 0 & 2.0 & 0.6 \\
\hline la/ stim on & $295(27)$ & 0 & 0.6 & 0.7 \\
\hline
\end{tabular}


bus pallidus and $\mathrm{STN},{ }^{31}$ and may represent a promising therapeutic avenue for the spasmodic dysphonias. A suitable target has not yet been identified; however, 1 report of DBS for DYT6 dystonia using the thalamic ventral lateral anterior nucleus (after failure at globus pallidus pars interna) demonstrated a significant improvement in spasmodic dysphonia symptoms. ${ }^{29}$

\section{Conclusions}

DBS has been discussed for approximately 15 years as a potential therapeutic modality for patients with EVT. However, to date, very few studies can be identified that have sought to systematically examine improvements in EVT following DBS surgery. EVT assessments in these studies are typically not comprehensive (e.g., they include direct laryngeal visualization and instrumental voice measures) and are inconsistent with time points used for data collection. Despite these limitations, studies do demonstrate positive findings, including reductions in the rate of F0 modulation and overall tremor severity. Consequently, we are in critical need of investigations that seek to systematically and prospectively determine the effectiveness of DBS as an intervention for EVT. These studies should include comprehensive laryngeal and voice assessment pre-, intra-, and postoperatively. Furthermore, comprehensive laryngeal and voice assessment should incorporate nasal endoscopy for direct laryngeal visualization and instrumental voice assessments including acoustics and aerodynamics, as well as perceptual analyses of voice by both the patient and clinicians. Comprehensive assessment of EVT prior to, during, and following DBS surgery will assist in the development of evidence-based guidelines regarding DBS as an effective intervention for vocal tremor. Findings have the potential to alter treatment paradigms for these difficult-to-serve patients.

\section{Acknowledgments}

We acknowledge Drs. Robert Sataloff and Gordon Baltuch for their guidance in the development of our vocal tremor program and the preparation of this study.

\section{References}

1. Barkmeier-Kraemer J, Lato A, Wiley K: Development of a speech treatment program for a client with essential vocal tremor. Semin Speech Lang 32:43-57, 2011

2. Benabid AL, Pollak P, Gao D, Hoffmann D, Limousin P, Gay E, et al: Chronic electrical stimulation of the ventralis intermedius nucleus of the thalamus as a treatment of movement disorders. J Neurosurg 84:203-214, 1996

3. Benabid AL, Pollak P, Louveau A, Henry S, de Rougemont $\mathrm{J}$ : Combined (thalamotomy and stimulation) stereotactic surgery of the VIM thalamic nucleus for bilateral Parkinson disease. Appl Neurophysiol 50:344-346, 1987

4. Carpenter MA, Pahwa R, Miyawaki KL, Wilkinson SB, Searl JP, Koller WC: Reduction in voice tremor under thalamic stimulation. Neurology 50:796-798, 1998

5. D'Alatri L, Paludetti G, Contarino MF, Galla S, Marchese MR, Bentivoglio AR: Effects of bilateral subthalamic nucleus stimulation and medication on parkinsonian speech impairment. J Voice 22:365-372, 2008

6. Dromey C, Kumar R, Lang AE, Lozano AM: An investigation of the effects of subthalamic nucleus stimulation on acoustic measures of voice. Mov Disord 15:1132-1138, 2000
7. Gamboa J, Jiménez-Jiménez FJ, Nieto A, Cobeta I, Vegas A, Ortí-Pareja M, et al: Acoustic voice analysis in patients with essential tremor. J Voice 12:444-452, 1998

8. Garonzik IM, Hua SE, Ohara S, Lenz FA: Intraoperative microelectrode and semi-microelectrode recording during the physiological localization of the thalamic nucleus ventral intermediate. Mov Disord 17 (Suppl 3):S135-S144, 2002

9. Gentil M, Chauvin P, Pinto S, Pollak P, Benabid AL: Effect of bilateral stimulation of the subthalamic nucleus on parkinsonian voice. Brain Lang 78:233-240, 2001

10. Gentil M, Tournier CL, Pollak P, Benabid AL: Effect of bilateral subthalamic nucleus stimulation and dopatherapy on oral control in Parkinson's disease. Eur Neurol 42:136-140, 1999

11. Gillivan-Murphy P, Miller N: Voice tremor: what we know and what we do not know. Curr Opin Otolaryngol Head Neck Surg 19:155-159, 2011

12. Groen JL, Ritz K, Contarino MF, van de Warrenburg BP, Aramideh M, Foncke EM, et al: DYT6 dystonia: mutation screening, phenotype, and response to deep brain stimulation. Mov Disord 25:2420-2427, 2010

13. Gross RE, Jones EG, Dostrovsky JO, Bergeron C, Lang AE, Lozano AM: Histological analysis of the location of effective thalamic stimulation for tremor. Case report. J Neurosurg 100:547-552, 2004

14. Hassler R: Architectonic organization of the thalamic nuclei, in Schaltenbrand G, Walker AE (eds): Stereotaxy of the Human Brain: Anatomical, Physiological and Clinical Applications. Stuttgart: Thieme, 1982, pp 140-180

15. Hua SE, Lenz FA: Posture-related oscillations in human cerebellar thalamus in essential tremor are enabled by voluntary motor circuits. J Neurophysiol 93:117-127, 2005

16. Ilinsky IA, Kultas-Ilinsky K: Motor thalamic circuits in primates with emphasis on the area targeted in treatment of movement disorders. Mov Disord 17 (Suppl 3):S9-S14, 2002

17. Jinnah HA, Berardelli A, Comella C, Defazio G, Delong MR, Factor $\mathrm{S}$, et al: The focal dystonias: current views and challenges for future research. Mov Disord 28:926-943, 2013

18. Kendall KA: Vocal tremor, in Grimaldi G, Manto M (eds): Mechanisms and Emerging Therapies in Tremor Disorders. New York: Springer, 2013, pp 235-248

19. Kleiner-Fisman G, Herzog J, Fisman DN, Tamma F, Lyons KE, Pahwa R, et al: Subthalamic nucleus deep brain stimulation: summary and meta-analysis of outcomes. Mov Disord 21 (Suppl 14):S290-S304, 2006

20. Klostermann F, Ehlen F, Vesper J, Nubel K, Gross M, Marzinzik F, et al: Effects of subthalamic deep brain stimulation on dysarthrophonia in Parkinson's disease. J Neurol Neurosurg Psychiatry 79:522-529, 2008

21. Lemaire JJ, Coste J, Ouchchane L, Caire F, Nuti C, Derost P, et al: Brain mapping in stereotactic surgery: a brief overview from the probabilistic targeting to the patient-based anatomic mapping. Neuroimage 37 (Suppl 1):S109-S115, 2007

22. Lenz FA, Dostrovsky JO, Kwan HC, Tasker RR, Yamashiro K, Murphy JT: Methods for microstimulation and recording of single neurons and evoked potentials in the human central nervous system. J Neurosurg 68:630-634, 1988

23. Lenz FA, Jaeger CJ, Seike MS, Lin YC, Reich SG: Singleneuron analysis of human thalamus in patients with intention tremor and other clinical signs of cerebellar disease. J Neurophysiol 87:2084-2094, 2002

24. Lester RA, Barkmeier-Kraemer J, Story BH: Physiologic and acoustic patterns of essential vocal tremor. J Voice 27:422432, 2013

25. Macchi G, Jones EG: Toward an agreement on terminology of nuclear and subnuclear divisions of the motor thalamus. $\mathbf{J}$ Neurosurg 86:670-685, 1997

26. Merati AL, Heman-Ackah YD, Abaza M, Altman KW, Sulica L, Belamowicz S: Common movement disorders affecting the larynx: a report from the neurolaryngology committee of the 
AAO-HNS. Otolaryngol Head Neck Surg 133:654-665, 2005

27. Molnar GF, Pilliar A, Lozano AM, Dostrovsky JO: Differences in neuronal firing rates in pallidal and cerebellar receiving areas of thalamus in patients with Parkinson's disease, essential tremor, and pain. J Neurophysiol 93:30943101,2005

28. Moringlane JR, Pützer M, Barry WJ: Bilateral high-frequency electrical impulses to the thalamus reduce voice tremor: acoustic and electroglottographic analysis. A case report. Eur Arch Otorhinolaryngol 261:334-336, 2004

29. Mure H, Morigaki R, Koizumi H, Okita S, Kawarai T, Miyamoto R, et al: Deep brain stimulation of the thalamic ventral lateral anterior nucleus for DYT6 dystonia. Stereotact Funct Neurosurg 92:393-396, 2014

30. Nambu A, Takada M, Inase M, Tokuno H: Dual somatotopical representations in the primate subthalamic nucleus: evidence for ordered but reversed body-map transformations from the primary motor cortex and the supplementary motor area. J Neurosci 16:2671-2683, 1996

31. Ostrem JL, Starr PA: Treatment of dystonia with deep brain stimulation. Neurotherapeutics 5:320-330, 2008

32. Papavassiliou E, Rau G, Heath S, Abosch A, Barbaro NM, Larson PS, et al: Thalamic deep brain stimulation for essential tremor: relation of lead location to outcome. Neurosurgery 62 (Suppl 2):884-894, 2008

33. Pinto S, Gentil M, Fraix V, Benabid AL, Pollak P: Bilateral subthalamic stimulation effects on oral force control in Parkinson's disease. J Neurol 250:179-187, 2003

34. Pitman MJ: Treatment of spasmodic dysphonia with a neuromodulating electrical implant. Laryngoscope 124:25372543, 2014

35. Puitzer M, Barry WJ, Moringlane JR: Effect of bilateral stimulation of the subthalamic nucleus on different speech subsystems in patients with Parkinson's disease. Clin Linguist Phon 22:957-973, 2008

36. Pützer M, Barry WJ, Moringlane JR: Effect of deep brain stimulation on different speech subsystems in patients with multiple sclerosis. J Voice 21:741-753, 2007

37. Rezai AR, Kopell BH, Gross RE, Vitek JL, Sharan AD, Limousin P, et al: Deep brain stimulation for Parkinson's disease: surgical issues. Mov Disord 21 (Suppl 14):S197-S218, 2006

38. Robbins JA, Logemann JA, Kirshner HS: Swallowing and speech production in Parkinson's disease. Ann Neurol 19:283-287, 1986

39. Rousseaux M, Krystkowiak P, Kozlowski O, Ozsancak C, Blond S, Destée A: Effects of subthalamic nucleus stimulation on parkinsonian dysarthria and speech intelligibility. J Neurol 251:327-334, 2004

40. Sataloff RT, Heuer RJ, Munz M, Yoon MS, Spiegel JR: Vocal tremor reduction with deep brain stimulation: a preliminary report. J Voice 16:132-135, 2002

41. Skodda S, Grönheit W, Schlegel U, Südmeyer M, Schnitzler A, Wojtecki L: Effect of subthalamic stimulation on voice and speech in Parkinson's disease: for the better or worse? Front Neurol 4:218, 2014
42. Taha JM, Janszen MA, Favre J: Thalamic deep brain stimulation for the treatment of head, voice, and bilateral limb tremor. J Neurosurg 91:68-72, 1999

43. Tsuboi T, Watanabe H, Tanaka Y, Ohdake R, Yoneyama N, Hara K, et al: Distinct phenotypes of speech and voice disorders in Parkinson's disease after subthalamic nucleus deep brain stimulation. J Neurol Neurosurg Psychiatry [epub ahead of print], 2014

44. Vitek JL, Ashe J, DeLong MR, Alexander GE: Physiologic properties and somatotopic organization of the primate motor thalamus. J Neurophysiol 71:1498-1513, 1994

45. Vitek JL, Ashe J, DeLong MR, Kaneoke Y: Microstimulation of primate motor thalamus: somatotopic organization and differential distribution of evoked motor responses among subnuclei. J Neurophysiol 75:2486-2495, 1996

46. Wang E, Verhagen Metman L, Bakay R, Arzbaecher J, Bernard B: The effect of unilateral electrostimulation of the subthalamic nucleus on respiratory/phonatory subsystems of speech production in Parkinson's disease - a preliminary report. Clin Linguist Phon 17:283-289, 2003

47. Wichmann T, Bergman H, DeLong MR: The primate subthalamic nucleus. I. Functional properties in intact animals. J Neurophysiol 72:494-506, 1994

48. Wolraich D, Vasile Marchis-Crisan C, Redding N, Khella SL, Mirza N: Laryngeal tremor: co-occurrence with other movement disorders. ORL J Otorhinolaryngol Relat Spec 72:291-294, 2010

49. Yoon MS, Munz M, Sataloff RT, Spiegel JR, Heuer RJ: Vocal tremor reduction with deep brain stimulation. Stereotact Funct Neurosurg 72:241-244, 1999

\section{Author Contributions}

Conception and design: Halpern, Ho, Erickson-DiRenzo. Acquisition of data: Ho, Erickson-DiRenzo, Sung. Analysis and interpretation of data: Ho, Erickson-DiRenzo. Drafting the article: Ho, Erickson-DiRenzo, Pendharkar. Critically revising the article: all authors. Reviewed submitted version of manuscript: Halpern, Ho. Approved the final version of the manuscript on behalf of all authors: Halpern.

\section{Supplemental Information \\ Videos}

Video 1, Media Player. http://mfile.akamai.com/21490/wmv/ digitalwbc.download.akamai.com/21492/wm.digitalsource-naregional/focus15-37_video_1.asx.

Video 1, Quicktime. http://mfile.akamai.com/21488/mov/ digitalwbc.download.akamai.com/21492/qt.digitalsource-global/ focus15-37_video_1.mov.

\section{Correspondence}

Casey H. Halpern, Department of Neurosurgery, Stanford University School of Medicine, 300 Pasteur Dr., Edwards Bldg./R-293, Stanford, CA 94305. email: chalpern@stanford.edu. 